\title{
A Study of Physics Teaching in the Preliminary Stage of 2+3+2 Integrated Multistage Training of Technical Personnel in High Technology
}

\author{
Shiju Sun ${ }^{1, a}$, Chengbin Liu ${ }^{2, *}, \mathrm{~b}$, Xue Wang ${ }^{1, c}$ \\ ${ }^{1}$ School of Telecommunication Engineering, Beijing Polytechnic, Beijing 100176, China; \\ ${ }^{2}$ Department of Hydraulic and Architectural Engineering, Beijing Vocational College of Agriculture, \\ Beijing 102442, China.

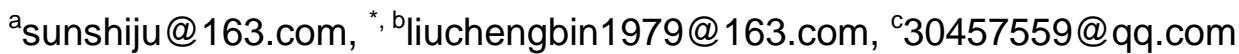

Keywords: Integrative training, teaching of physics, innovative thinking, innovation capability.

\begin{abstract}
The pilot project for Integrated Multistage Training of Technical Personnel in High Technology (the Project) has been carried out for nearly two years since it was launched in 2015 by the Beijing Municipal Commission of Education. This paper presents the objective of the Project and the subjects it offers and discusses how to accordingly foster students' innovative thinking and innovation capability, help them lay the basis for lifelong learning, and promote their physical and mental health during physics teaching in the preliminary stage. The central idea is to ensure the quality of the personnel training and adapt teaching of physics to the demands of the ongoing vocational education reform.
\end{abstract}

\section{Introduction}

As the capital Beijing has grown into a global city, its economic development and industrial structure tend to be more dependent on technology upgrade and increasingly knowledge and technology intensive. Talents specializing in sophisticated technology are urgently needed by big international companies and high-end industrial clusters. In this context, the Beijing Municipal Commission of Education made the Notice on Implementing a Pilot Project for Integrated Multistage Training of Technical Personnel in High Technology (JJZC [2015] 5) on March 19, 2015, and the Notice on Implementing the Pilot Project for Integrated Multistage Training of Technical Personnel in High Technology in 2016 (JJZC [2016] 5) (hereafter the Notice) on May 11, 2016. This Project is intended to cultivate technical personnel in high technology that meets the demand of Beijing's growing economy, push forward the comprehensive education reform, and explore new training methods. The Notice requires efforts to break down existing structural and institutional barriers and integrate high-quality educational resources from educational institutions at all levels and of all types in order to perfect the prevailing vocational education system and construct a joint platform for training. In this way, the vocational schools are able to improve their educational competence and quality, prepare students for a career in advanced technology, and make grater contribution to the economic and social development in Beijing.

The Project supports cooperation between some vocational schools and senior high schools of quality, universities, and domestic and foreign enterprises. This allowed vocational schools to give priority to subjects that match demands of various industries and provide better higher vocational education and professional education at the undergraduate level. These schools recruit outstanding graduates of junior high schools across the city and teach them general courses designed for senior high school education. After that, the students will enter higher vocational education and then undergraduate education. In other words, the students are required to complete preliminary courses in the first two years and then go through three years of vocational education, followed by two years of undergraduate education. The three continuous stages constitute a seven-year $(2+3+2)$ progressive, integrated training model[1].

The students enrolled in the trial project are freed from the pressure to pass the college entrance examination, but they need to face higher requirements in terms of all-round qualities, sense of 
innovation, creativity, and personal capacity for sustainable development. Though they are too young to think deeply about their career choice and development in the future, the Project provides them with more rights and opportunities to make independent decision on their career. This training model enables every student to fully show their individual characters and provokes their enthusiasm for learning.

\section{Significance of physics teaching in the Project}

Made in China 2025, a program of action issued by the State Council on May 8, 2015, emphasizes that manufacturing built, rejuvenates, and strengthens China. It also points out that China's manufacturing sector is huge but not strong enough compared with manufacturing powers, especially in terms of capacity for independent innovation, resources, efficiency, and industrial structure. Under the new strategy of manufacturing power, the manufacturing sector imposes higher requirements on technical personnel. Manufacturers are now in need of technical talents that are proficient in new and core technology, technical specialists and experts that are able to constantly renew their knowledge base and upgrade skills, and senior talents that are capable of carrying out research and development in technology[2]. To meet these demands, the schools involved in the ongoing integrated multistage training project offer a wide range of subjects, such as electronics and information, machinery and computer numerical control, electric engineering and automation, vehicle and transportation, architecture, surveying and mapping, economics and management, food and biology, arts and design. These subjects cover nearly all high-tech industries in which Beijing will invest heavily over the next five years, including big data and cloud computing, intelligent precision machining, intelligent network system adjustment and control, biomedical testing, etc.

Physics, one of the major disciplines taught during basic education, advocates rational thinking and emphasizes logical reasoning. It helps people appreciate the beauty of the universe and comprehend truths about everything. The development of physics has boosted technological improvement, triggered industrial revolutions one after another, and promoted social progress. In particular, modern physics has become the foundation of high technologies. Among the subjects offered by the Project for the higher vocational and undergraduate education, those about high technologies must be based on physics. Therefore, exploring appropriate approaches to physics teaching in the preliminary stage of integrated training is not only required by the current education reform, but is also a necessary effort to make the training forward-looking.

\section{Innovation-oriented education to foster innovation capability}

The very essence of physics does not lie in any principle or law, but in the spirit of innovation it embodies. Constant exploration, discoveries and innovation keep driving the development of this discipline. It is innovation that makes physics what it is today[3].

It is widely recognized that interest is the best teacher. However, the traditional education model is too undiversified. Normally, the classroom atmosphere very serious and course content is too difficult to understand. Over time, students tend to lose enthusiasm and activity for learning. Therefore, teachers should first change their monotonous physics lessons to light-hearted and interesting lessons so that students will be willing to study actively and able to enjoy the lessons. To this end, proper course design is very important. New elements that can inspire students to explore the unknown in search of deeper and broader knowledge can be added to basic knowledge. In class, teachers provide only guides and tips, and students are required to perform exploration by themselves. In this way, students are able to play an active role in class and generate interest in physics, enthusiasm for knowledge and confidence. After a long period of study, they will have their own views on what they have learned and seen. Teachers should encourage them to think independently and express doubts even though their views may be unreasonable sometimes. Additionally, debates between teachers and students can be introduced into class. Through debates with teachers, students 
will have more active mind and improved ability to think and analyze, thereby gaining deeper understanding of theoretical knowledge and growing interest in physics.

Great importance should be given to physical experiments. Since physics is an experimental science, physics experiments hold an important position in physics education. Experiments give rise to, and verify, theories, and act as a bridge between theoretical research and production practices. Independent operations and observations included in physics experiments allow students to take a proactive role in learning physics. Miraculous phenomena observed during experiments encourage their thirst for knowledge. As a result, they will be willing to explore the physical principles behind various phenomena and to discuss, and even debate, with other group members. These are expected to spark a spirit of innovation among them.

\section{Application of Information Technology to Physics Teaching}

The first advantage of multimedia technology is that it can give a visual expression (e.g. light and shadow) of experiments that are undoable in class. It helps strengthen students' ability to comprehend and perceive physical phenomena. Therefore, it is necessary to apply multimedia technology to physics teaching in class. Teachers are required to meticulously design and renew multimedia courseware rather than simply download and copy on-line resources or repeatedly use existing materials. They should make elaborate teaching plans on how to sketch general outlines and impart key and difficult knowledge by proper use of various functions of multimedia. Instructive, scientific, and artistic multimedia courseware will be able to maximize learners' potential and thereby improve the results and quality of teaching.

Additionally, extracurricular simulation experiments can be performed using information technology. In a conventional laboratory setting, experimental operations may lead to significant errors in results of some physics experiments due to environmental restrictions. In simulation experiments, the simulation software can provide ideal experimental environments, increasing efficiency and success rate of experiments. Moreover, simulation experiments cal also build up students' interest in learning physics and enhance their thinking skills and innovation capability.

\section{Close connections with physics education at lower secondary and undergraduate levels}

The preliminary stage of integrated training roughly corresponds to higher secondary education. The crucial difference between them lies in physics teaching. Physics education in this stage needs to help students go deeper based on junior high school physics and lay the foundation for the subsequent studying of college physics. Junior high school physics is simple and easy; it is primarily aimed at guiding students to develop the habit of using physical knowledge to explain natural phenomena. During the integrated training, the physics course includes more theoretical and abstract knowledge, which usually needs to be presented using idealized physic models. Therefore, students are required to perform explorations and study basic skills and methods needed. The objective of physics education in this stage is to strengthen students' practical ability and thinking skills.

College physics is a compulsory course in the stage of higher vocational education. Compared to the previous stage, physics education in this stage puts more emphasis on basics, contemporary trend, and frontiers of physics, applications of physics in future high technologies, and in-depth explanations of physical laws. It aims to achieve combination of basics with frontiers, classical physics with modern physics, and theories with applications. Methods and content used in teaching and studying also differ from the previous stage. The physics course includes voluminous difficult knowledge and proceeds at a fast pace. It requires students to do more explorations and thinking. Therefore, self-control is especially important to them. Meanwhile, teachers need to organize activities like thematic experiments, skills contests, and career planning to tap students' potential and motivate them to read, think, discuss, and do experiments. Students can constantly upgrade their knowledge and practical skills by participating in these activities. 


\section{Be physics teachers that never stop learning}

In terms of the relationship between teachers and students, teachers serve as a facilitator in students' learning. In terms of the relationship between teaching and research, teachers are researchers in education. In terms of the relationship between teaching and curriculum, teachers are builders and developers of curriculum. During the implementation of the Project over the past two years, the teachers involved in the Project have innovatively developed curriculums, teaching plans, and methods suitable for integrated multistage training, because there has been no available experience from domestic or foreign teachers for reference. This education reform is a test of teachers' teaching ability as well as a motivator for the teaching staff. If teachers still follow the traditional teaching models adopted in regular higher secondary and vocational education, they would run counter to the intention of the Project, impair its vitality, and impede the progress towards the goal of the Project. Therefore, teachers must keep learning and exploring effective teaching methods to meet the goal of the Project and pursue a lifelong career as both teachers and learners. Keeping learning is essential for their career development and improvement in teaching quality. Physics teaching in the preliminary stage of training must adapt to demands of development modern high technologies and be capable of enhancing all-round qualities of students. Based on the concept of "learning how to be a teacher throughout life”, teachers in different subjects should pay close attention to the dynamics of students, refresh teaching resources, and combine new technologies with basic concepts and principles. In addition, they should give students more opportunities to think independently, create a sound education environment, and guide them to choose suitable subjects to study in the following stages.

\section{Summary}

The preliminary stage of training is characterized by deep cooperation between regular senior high schools and higher vocational schools. Teachers from regular senior high schools and experienced teachers from higher vocational schools jointly prepare lessons, listen to each others' lessons, share experience, and discuss teaching progress, models and methods. Unlike traditional exam-oriented education and vocational education at the secondary level, this stage of education is intended to prepare students for vocational and higher education in the subsequent five years and attaches more importance to students' all-round ability. Physics is not only a basis for the development of other natural sciences, but also an important source of development of technologies, especially high technologies. Physics teaching needs synergies among multiple factors, such as physics experiments, application of information technology, active role of students, and leading role of teachers. Teachers should make great efforts to fully tap students' potential, nurture their innovative thinking, and keep learning and exploring, in order to cultivate more creative technical personnel in high technology.

\section{Acknowledgements}

This work was financially supported by the Talents Training Project of Beijing Polytechnic(No. CJRC-SZDW-2015/001/032, No. CJGX2016-JX-26/012) and the School-level Research Project of Beijing Vocational College of Agriculture(No. XY-BS-15-03).

\section{References}

[1] Hua Zhang, Yonghui Zhang, Exploration on the teaching mode of "2+3+2" in the background of through training reform, Education and Vocation. 16 (2016) 118-120.

[2] Jiafeng Liang, Thinking and practice of "2+3+2" high technical skill talents through training, Higher Education Development Study. 9 (2015) 21-23.

[3] Zemin Chen, Four ideas for teaching foundamental physics, Physics and Engineering. 6 (2006) 4-10. 